University of Nebraska - Lincoln

DigitalCommons@University of Nebraska - Lincoln

Publications from USDA-ARS / UNL Faculty

U.S. Department of Agriculture: Agricultural

Research Service, Lincoln, Nebraska

2004

Inbreeding levels of two Ustilago maydis populations

Charles W. Barnes

USDA-ARS, barn0107@umn.edu

Les J. Szabo

USDA-ARS

Georgiana May

University of Minnesota

James V. Groth

University of Minnesota

Follow this and additional works at: https://digitalcommons.unl.edu/usdaarsfacpub

Barnes, Charles W.; Szabo, Les J.; May, Georgiana; and Groth, James V., "Inbreeding levels of two Ustilago maydis populations" (2004). Publications from USDA-ARS / UNL Faculty. 1556.

https://digitalcommons.unl.edu/usdaarsfacpub/1556

This Article is brought to you for free and open access by the U.S. Department of Agriculture: Agricultural Research Service, Lincoln, Nebraska at DigitalCommons@University of Nebraska - Lincoln. It has been accepted for inclusion in Publications from USDA-ARS / UNL Faculty by an authorized administrator of DigitalCommons@University of Nebraska - Lincoln. 
Mycologia, 96(6), 2004, pp. 1236-1244.

(C) 2004 by The Mycological Society of America, Lawrence, KS 66044-8897

\section{Inbreeding levels of two Ustilago maydis populations}

Charles W. Barnes ${ }^{1}$

USDA-ARS Cereal Disease Laboratory, 1551 Lindig

Street, St. Paul, Minnesota 55108-6052

Les J. Szabo

USDA-ARS Cereal Disease Laboratory and Department of Plant Pathology, University of Minnesota, 1551

Lindig St., St. Paul, Minnesota 55108-6052

Georgiana May

Department of Ecology, Evolution and Behavior, University of Minnesota, 100 Ecology Building, 1987

Upper Buford Circle, St. Paul, Minnesota 55108-6052

James V. Groth

Department of Plant Pathology, University of Minnesota, 495 Borlaug Hall, 1991 Upper Burford

Circle, St. Paul, Minnesota 55108-6052

Abstract: Little is known about the population mating behavior of the smut fungus Ustilago maydis DC (Corda). To determine the amount of inbreeding that occurs in local $U$. maydis populations, two cornfields were sampled, one in North America (NA) at Le Sueur, Minnesota, and one in South America (SA) at Tarariras, Uruguay. These fields were chosen because of their geographic isolation and host management differences. Inbreeding coefficients $\left(F_{i s}\right)$ were calculated using data derived from amplified fragment length polymorphism (AFLP) markers. Mean $F_{\text {is }}$ values estimated for both the NA $(-0.08)$, and the SA (-0.02) populations statistically are not different from zero. The results of this study demonstrate that the $U$. maydis population structure in both cornfields results predominately from out-crossing and suggests that teliospores infrequently act as single infection units. The genetic differentiation between populations was high $\left(\mathrm{F}_{\mathrm{st}}=0.25\right)$.

Key words: corn smut, Hardy-Weinberg Equilibrium, heterozygosity, maximum parsimony analysis, Wright's inbreeding coefficient

\section{INTRODUCTION}

Ustilago maydis DC (Corda) has been used as a model organism for the study of signal transduction path-

\footnotetext{
Accepted for publication June 4, 2004.

${ }^{1}$ Corresponding author. E-mail: barn0107@umn.edu
}

ways regulating mating, filamentous growth and virulence (Hartmann et al 1999, Andrews 2000, Xu 2000). However, much less is known about the field biology of the organism. U. maydis is a dimorphic pathogenic fungus that infects maize (Zea mays L.) and corn's close relatives, the teosintes, and occurs wherever corn grows. Yield losses due to $U$. maydis infection can be substantial on susceptible cultivars of sweet corn, but losses rarely exceed $2 \%$ annually over large areas (Shurtleff 1980). For widespread pathogens, knowing the degree of out-crossing and whether mating behavior is consistent across populations is important to the understanding of population dynamics. Mating behavior of pathogen populations is dependent on both the mating incompatibility system and the population structure of the host.

Teliospores are spread by wind and over winter on plant debris and in soil and provide inoculum to begin the $U$. maydis life cycle in the spring (Christensen 1963), as they germinate to form haploid sporidia. The primary sporidia subsequently grow by budding as yeast-like secondary sporidia; these sporidia also may survive on crop debris as saprophytes (Webster 1980). Two compatible haploid cells, differing in alleles of $a$ and $b$ mating-type loci, mate to form an infectious dikaryon (Rowell and DeVay 1954, Banuett 1995). Self-mating between sibling sporidia (i.e. sporidia from the same teliospore) is possible because meiosis at the time of teliospore germination produce compatible haploids. Infection of a susceptible corn plant by the dikaryon proceeds either through direct penetration between epidermal cell after appresoria formation (Snetselaar and Mims 1992, 1993) or by growth through stomata or wounds (Christensen 1963, Alexopoulos et al 1996). Dikaryotic hyphae subsequently proliferate and ramify intercellularly, eventually forming galls in infected plant tissue (Snetselaar and Mims 1994, Banuett and Herskowitz 1996). Galls likely are formed through secretion of hormones or by stimulating plant hormone production, such as auxin, in infected tissue (Agrios 1997). Galls can occur on all young growing plant tissue; the male and female inflorescences, stalk, and leaf (Gillissen et al 1992). During gall maturation hyphae fragment, which then develop into thick-walled diploid teliospores (Webster 1980).

In North and South America, geographical sepa- 
NA SA

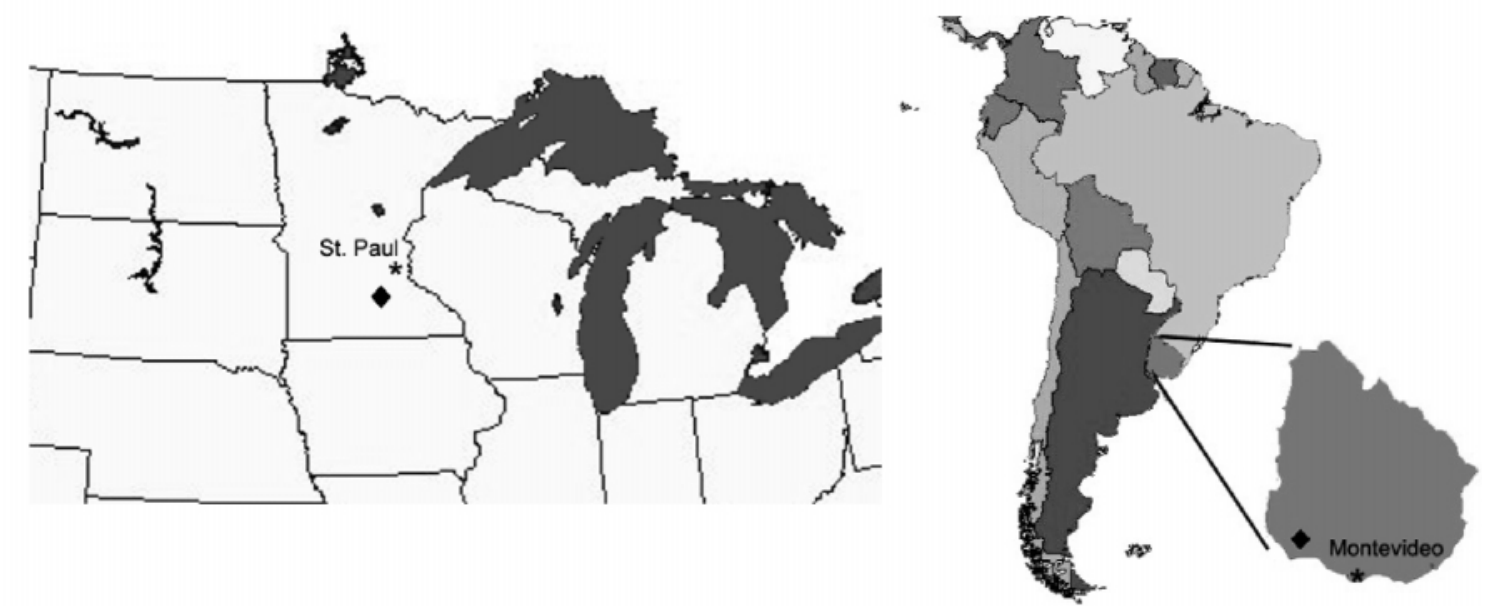

FIG. 1. Location of cornfields sampled ( ) in North America (NA), Le Sueur, Minnesota $\left(44.27 .48^{\circ} \mathrm{N}, 93.54 .22^{\circ} \mathrm{W}\right)$, and in South America (SA), near Tarariras, Uruguay $\left(34.14 .18^{\circ} \mathrm{S}, 57.34 .56^{\circ} \mathrm{W}\right)$.

ration and differences in host plant population structure and management might have an impact on the mating behavior of $U$. maydis populations. In North America (NA), maize has been cultivated extensively for decades on a continuous area of land stretching from Minnesota south to Nebraska and east to Ohio, a region known as the Corn Belt. In contrast, in many regions of South America (SA), maize is planted in relatively small, isolated fields. In addition, maize is often not a dominant crop in these regions and the crops will be rotated so that corn is not grown continuously on the same field. The stark differences in management practices between these regions were chosen to determine if these practices lead to differences in the $U$. maydis population structure. The lower density of maize in SA likely would maintain reduced gene flow between more isolated smut populations, and thus more inbreeding within local populations would be expected, compared to larger and more continuous NA smut populations. Continued inbreeding would result in a reduction in the average frequency of heterozygosity within a population, relative to random mating. Heterozygote deficiency relative to the expectation of random mating can be estimated by Wright's inbreeding coefficient $\left(\mathrm{F}_{\mathrm{is}}\right.$, Wright 1965). Great genetic variation among populations of $U$. maydis has been found (Zambino et al 1997, Valverde et al 2000) suggesting that inbreeding might be infrequent. However, these studies did not directly assess levels of inbreeding.

In the present study, genetic variation in two $U$. maydis populations was examined through the analysis of molecular markers generated by amplified fragment length polymorphism (AFLP). Two corn- fields, one in North America (NA) at Le Sueur, Minnesota, and one in South America (SA) at Tarariras, Uruguay, were studied. The two sites were selected because they are geographically isolated from one another, differ greatly in size and are subject to different management practices. The objectives of this study were (i) to determine the breeding structure of the $U$. maydis populations from these two cornfields, and (ii) to compare population genetic structure of the SA and NA populations.

\section{METHODS AND MATERIALS}

Field plot locations, sample collection and storage.-Corn smut galls were collected from two locations. On 13 Aug 1998 galls were collected from dent corn near Le Sueur, Minnesota $\left(44.27 .48^{\circ} \mathrm{N}, 93.54 .22^{\circ} \mathrm{W}\right.$; FIG. 1$)$ on a large privately owned commercial field (total acreage unknown). Sixty samples were collected in six transects, spaced $30 \mathrm{~m}$ apart, with 10 samples per transect, also $30 \mathrm{~m}$ apart, covering an area of approximately 5.4 ha, representing a fraction of the total field size. The majority of galls collected in this field were from corn ears, most nearing maturity. Proprietors of the field reported $U$. maydis occurred more frequently than in previous years due to a spring hailstorm that might have created wounds on the corn plants. The sampled field was surrounded by other cornfields in an area of heavy corn production in southern Minnesota. U. maydis was observed in adjacent fields.

Samples were collected from a second location near Tarariras, Uruguay, (approximately $30 \mathrm{~km}$ northeast of Colonia del Sacramento, $34.14 .18^{\circ} \mathrm{S}, 57.34 .56^{\circ} \mathrm{W}$; Fig. 1) on $4 \mathrm{Apr}$ 2000 from a farmer's field planted with Dekalb 821 hybrid corn. The field was about 6 ha. Due to record-setting dry conditions that year, the field was harvested for silage. Incidence of $U$. maydis infection was greater than $30 \%$, with 
all observed infections on the ears, and all fungal galls were dry and fully mature. The field was sampled in the same manner as the field in Le Sueur, Minnesota, with samples and transects $30 \mathrm{~m}$ apart. However, because this field was small, transects were extended to cover the entire field, resulting in a sample of 73 galls. Alfalfa had been grown in this location the two previous years, and the nearest neighboring field of corn was more than $1 \mathrm{~km}$ away. Moreover, no other cornfields were observed within more than $5 \mathrm{~km}$.

Each sample consisted of a small amount of teliospores collected directly into sterile $2 \mathrm{~mL}$ polypropylene microcentrifuge tubes with rubber O-ring caps. Each sample was placed in a separate tube and sealed at the sample site. Once in the laboratory, the caps were removed and the samples were placed in a sealed glass chamber with desiccant for a minimum of $1 \mathrm{wk}$ or until the samples were thoroughly dry. Dried samples then were recapped and stored at room temperature in a dark, dry location.

Cultures.-Teliospores from 32 randomly chosen galls from each field were surfaced sterilized for $0.5 \mathrm{~h}$ in a $1.0 \mathrm{~mL}$ solution of sterile double-distilled $\mathrm{H}_{2} \mathrm{O}$ (DDW), $0.1 \%$ $\mathrm{CuSO}_{4}$ and $0.5 \mathrm{mg}$ of oxytetracycline dehydrate. Roughly 500 teliospores $/ \mathrm{mL}$ were spread onto a thin section of potato-dextrose agar (PDA). After approximately $24 \mathrm{~h}$ (at room temperature), teliospores germinated and produced the primary sporidia by meiosis. A deFonbrun micromanipulator was used to isolate the four haploid primary sporidia from the tetrad. Individual sporidia from these tetrads were grown on PDA, and a loop from each sporidial colony was transferred to $40 \mathrm{~mL}$ of sterile PDB with Streptomycin (10 $\mathrm{mg} / \mathrm{mL}$ ), shaken at $120 \mathrm{rpm}$ for $48 \mathrm{~h}$ at $24 \mathrm{C}$, the time required for cultures to reach maximum density. Approximately $100 \mu \mathrm{L}$ of culture was removed, mixed with ovendried silica gel and placed at $-20 \mathrm{C}$ for storage of the living cultures. The remaining culture was transferred to a sterile $50 \mathrm{~mL}$ conical tube, mixed with approximately $0.5 \mathrm{~g}$ of sterile glass beads and centrifuged $15 \mathrm{~min}$ at $10000 \mathrm{rpm}$. The pellet was placed in liquid nitrogen, immediately lyophilized, and stored in sterile $2 \mathrm{~mL}$ tubes at $-20 \mathrm{C}$ until DNA extraction.

DNA isolation and AFLP analysis.-DNA was extracted from three of the four sporidial colonies of each tetrad, allowing recovery of both alleles at heterozygous markers. Isolate names were derived using the collection transect and sample number and sporidial number of the ordered tetrad (TABLE I). Freeze-dried sporidia were ground by shaking the lyophilized sample/glass bead mixture in a Savant FastPrep shaker (FP120, Holbrook, New York) for 10 $\mathrm{s}$ at a speed setting of 5 (Zambino 2002). DNA was extracted using a modification of the CTAB method described by Anikster et al (2004). The DNA was quantified using a DyNA Quant 200 Fluorometer (Hoefer) and verified on an agarose gel.

The AFLP fingerprinting (Vos et al 1995) was performed with the AFLP ${ }^{\circledR}$ Expression Analysis Kit (LI-COR, Lincoln, Nebraska). The enzymes EcoRI and MseI were used to digest $100 \mathrm{ng}$ of genomic DNA from each sample. Preselective amplification was performed using EcoRI-A and MseI-C primers. Selective amplification was performed with four fluores-
TABLE I. Ustilago maydis sporidia isolates used in this study

\begin{tabular}{|c|c|c|c|c|c|}
\hline \multicolumn{3}{|c|}{ North America ${ }^{a}$} & \multicolumn{3}{|c|}{ South Americab } \\
\hline & & Sporidia & & & Sporidia \\
\hline Transect $^{\mathrm{c}}$ & Sample & No. ${ }^{\mathrm{d}}$ & Transect $^{\mathrm{c}}$ & Sample ${ }^{c}$ & No. ${ }^{\mathrm{d}}$ \\
\hline \multirow[t]{5}{*}{1} & 1 & $1,2,3$ & 1 & 1 & $1,2,3$ \\
\hline & 2 & $2,3,4$ & & 2 & $1,2,3$ \\
\hline & 6 & $1,2,4$ & & 3 & $2,3,4$ \\
\hline & 7 & $2,3,4$ & & 4 & $1,2,3$ \\
\hline & 9 & $1,2,3$ & & 5 & $1,2,3$ \\
\hline \multirow[t]{6}{*}{2} & 1 & $1,2,4$ & & 6 & $1,2,3$ \\
\hline & 2 & $1,2,4$ & & 7 & $1,2,3$ \\
\hline & 3 & $1,2,3$ & & 8 & $1,2,3$ \\
\hline & 6 & $1,2,4$ & & 9 & $1,2,4$ \\
\hline & 7 & $1,2,4$ & & 10 & $1,2,3$ \\
\hline & 8 & $1,3,4$ & & 11 & $1,2,4$ \\
\hline \multirow[t]{5}{*}{3} & 1 & $1,2,4$ & & 12 & $2,3,4$ \\
\hline & 3 & $1,2,4$ & & 13 & $1,2,4$ \\
\hline & 4 & $1,2,4$ & 2 & 1 & $1,2,3$ \\
\hline & 5 & $1,2,4$ & & 2 & $1,2,3$ \\
\hline & 7 & $1,2,4$ & & 3 & $1,2,3$ \\
\hline \multirow[t]{8}{*}{4} & 1 & $1,2,4$ & & 6 & $1,2,3$ \\
\hline & 2 & $1,2,4$ & & 8 & $1,2,3$ \\
\hline & 3 & $1,2,3$ & & 12 & $2,3,4$ \\
\hline & 4 & $1,2,3$ & 3 & 1 & $1,2,3$ \\
\hline & 7 & $1,2,3$ & & 4 & $1,2,4$ \\
\hline & 8 & $1,2,4$ & & 5 & $1,2,3$ \\
\hline & 9 & $1,2,3$ & & 6 & $1,2,3$ \\
\hline & 10 & $1,2,3$ & 4 & 1 & $2,3,4$ \\
\hline \multirow[t]{7}{*}{5} & 1 & $1,2,3$ & & 2 & $1,2,3$ \\
\hline & 2 & $1,2,4$ & & 3 & $1,2,3$ \\
\hline & 5 & $1,2,4$ & & 4 & $1,2,3$ \\
\hline & 6 & $1,2,3$ & 6 & 1 & $1,2,4$ \\
\hline & 8 & $1,2,4$ & & 2 & $1,2,4$ \\
\hline & 9 & $1,2,4$ & & 3 & $2,3,4$ \\
\hline & 11 & $1,2,4$ & & 4 & $1,2,4$ \\
\hline 6 & 2 & $1,2,4$ & & 5 & $1,2,4$ \\
\hline
\end{tabular}

a Samples collected in North America from Le Sueur, Minnesota.

b Samples collected in South America from Tarariras, Uruguay.

c Transects and consecutive samples (teliospores) were spaced $30 \mathrm{~m}$ apart.

${ }^{d}$ Sporidia No. is the tetrad number of the sporidia used to determine the heterozygous or homozygous state of the parent teliospore. Isolate names were derived from the transect number, sample number, and sporidial number, such that isolate 3-4-2 is from transect 3, sample 4, and the second sporidia from the ordered tetrad of that sample.

cently labeled primers sets: EcoRI-AA/MseI-CA, EcoRI-AA/ MseI-CC, EcoRI-AA/MseI-CG, and EcoRI-AA/MseI-CT. All amplifications were carried out using a Peltier Thermal Cycler-100 (MJ Research, Waltham, Massachusetts), and products analyzed on a DNA analyzer Gene Readir 4200 (LICOR, Lincoln, Nebraska).

Polymorphic markers, between 100 and 700 base pairs in size, were scored as present (1), absent (0), or ambiguous 
(?) for each haploid isolate using the Gene ImagIR 3.55 software (Scanalytic Inc.). All markers were scored twice, either by two independent scorers, or by rescoring by one person at another time. Data analysis was performed using only high quality, unambiguous markers. For each of the three haploid sporidia isolated as tetrads from diploid teliospores, both alleles were determined for each AFLP marker. Knowing the allelic constitution of the parent teliospore, the homozygous or heterozygous state of the teliospore was determined, giving a genotypic evaluation of heterozygosity.

Population genetic analysis._Inbreeding. Population genetic analyses were conducted using POPGENE (Yeh et al 1997), with specific calculations cited for each test. In inbreeding populations, average heterozygosity decreases relative to the average heterozygosity expected with random mating within the same population. Inbreeding is estimated as the deficiency in observed heterozygote frequencies relative to the Hardy-Weinberg equilibrium (HWE) expectation of 2pq, where $\mathrm{p}$ and $\mathrm{q}$ are observed individual frequencies for alleles. The inbreeding coefficient $\left(\mathrm{F}_{\mathrm{is}}\right)$ at each marker was calculated as

$$
\mathrm{F}_{\text {is }}=\mathrm{H}_{\mathrm{s}}-\mathrm{H}_{\mathrm{i}} / \mathrm{H}_{\mathrm{s}}
$$

where $\mathrm{H}_{\mathrm{s}}$ is the heterozygosity expected through random mating within the subpopulation and $\mathrm{H}_{\mathrm{i}}$ is the observed heterozygosity of individuals within the subpopulation (Wright 1965) determined from the reconstructed diploid type. $\mathrm{F}_{\text {is }}$ values were estimated using only strongly polymorphic markers, defined as markers with allele frequencies of 30-70\% (Burt et al 1996). Markers that showed significant linkage disequilibrium were not used in calculations of $\mathrm{F}_{\mathrm{is}}$. A one-sample $t$-test was used to determine whether the mean $\mathrm{F}_{\text {is }}$ score in each population was statistically different from zero using Statistix for Windows (Analytical Software 1998). Significant departures from HWE were determined by $\chi^{2}$ and likelihood ratio $\left(\mathrm{G}^{2}\right)$ tests by Levene's (1949) algorithm. The algorithm calculates the probability of the expected frequency of homozygotes based on observed frequencies of alleles at each marker and assuming HWE.

Linkage disequilibrium was used to determine whether the AFLP markers were segregating independently by using Burrows' unbiased composite measure of linkage disequilibria between pairs of markers and $\chi^{2}$ goodness-of-fit tests for significance, as computed in Weir (1979). The composite measure was preferred because it makes no assumption about the mating system, where other methods may assume random mating (Weir 1979). Linkage disequilibrium between all pairs of strongly polymorphic markers was assessed. Tests for association between specific $b$ mating-type alleles and alleles at the strongly polymorphic markers were conducted using two-way contingency tests (Sokal and Rohlf 1981).

Comparisons between populations. The distribution of $\mathrm{F}_{\text {is }}$ values for the two populations were compared by plotting standard bar graphs of $F_{\text {is }}$ values rounded to the nearest whole number. Normality of the data was evaluated by a Wilk-Shapiro Rankit Plot using Statistix for Windows (Analytical Software 1998).

$\mathrm{F}_{\mathrm{st}}$, a parameter similar to $\mathrm{F}_{\mathrm{is}}$, was calculated to compare
TABLE II. The number of AFLP amplicons scored from $U$. maydis samples

\begin{tabular}{lcc}
\hline \hline \multirow{2}{*}{ Primer pair } & \multicolumn{2}{c}{ Scored amplicons ${ }^{\mathrm{a}}$} \\
\cline { 2 - 3 } Msel-CA EcoRI-AA & $\mathrm{NA}^{\mathrm{b}}$ & $\mathrm{SA}^{\mathrm{c}}$ \\
Msel-CC EcoRI-AA & 42 & 40 \\
Msel-CG EcoRI-AA & 34 & 30 \\
Msel-CT EcoRI-AA & 42 & 39 \\
Total & 50 & 45 \\
\hline
\end{tabular}

a Only amplicons that were present in all experiments for each primer pair combination, polymorphic among two or more individuals, and of high quality by agreement among experiments were included.

b Samples collected in North America (NA) from Le Sueur, Minnesota.

c Samples collected in South America (SA) from Tarariras, Uruguay.

heterozygosity within the NA and SA subpopulations $\left(\mathrm{H}_{\mathrm{s}}\right)$ relative to heterozygosity of the total population $\left(\mathrm{H}_{\mathrm{t}}\right)$, estimated using 205 polymorphic markers in the total population.

$$
\mathrm{F}_{\mathrm{st}}=\mathrm{H}_{\mathrm{t}}-\mathrm{H}_{\mathrm{s}} / \mathrm{H}_{\mathrm{t}}
$$

For populations at equilibrium between migration and drift, $\mathrm{F}_{\text {st }}$ reflects population differentiation and reduction in heterozygosity relative to the heterozygote frequencies expected for the total population. The estimate of gene flow between the two fields $\left(\mathrm{N}_{\mathrm{m}}\right)$ was calculated from the estimate of $F_{\text {st }}$ (Slatkin and Barton 1989) as

$$
\mathrm{N}_{\mathrm{m}}=1 / 4\left(1 / \mathrm{F}_{\mathrm{st}}-1\right)
$$

Maximum parsimony analysis was performed using PAUP $4.0 \mathrm{b5}$ (Swofford 2001) to assess variation in the total population, with tree bisection-reconstruction (TBR) branch swapping and saving multiple parsimonious trees. One hundred nonparametric bootstrap replicates were performed with simple taxon addition and TBR branch swapping. Relationships among isolates were analyzed to determine relatedness within and between $U$. maydis populations.

\section{RESULTS}

AFLP markers.-Four AFLP primer pair combinations (EcoR1-AA versus Mse1-CN) generated 168 and 154 amplicons for the NA and SA populations, respectively (TABLE II). Closely linked markers indicated by linkage disequilibrium analyses, and those that were invariant in both populations were removed from the combined total of 322 markers, leaving 205 markers available for dendrogram and $\mathrm{F}_{\mathrm{st}}$ analyses. Of the 205 polymorphic markers, 86 (42\%) demonstrated shared polymorphism between the two populations and 119 (58\%) were polymorphic in one population but fixed in the other population. 

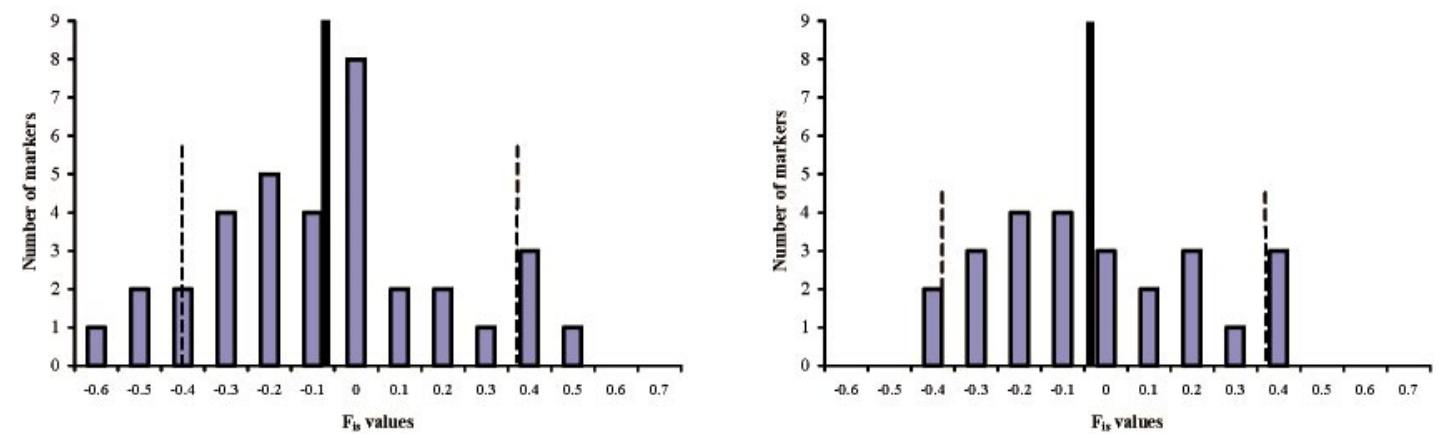

FIG. 2. Histograms of inbreeding coefficients $\left(\mathrm{F}_{\mathrm{is}}\right)$ of strongly polymorphic markers from Le Sueur, Minnesota (a), and Tarariras, Uruguay (b), U. maydis populations. The black vertical bars indicate average $\mathrm{F}_{\text {is }}$ values for each population based on calculations developed by Weir (1996) in POPGENE. Raw data points were rounded to the nearest whole number for graphical presentation only. Values outside dashed vertical lines are significantly different from HWE. Positive values indicate decreases in heterozygosity. Average $\mathrm{F}_{\text {is }}$ values are not significantly different from zero, indicating both populations are mating randomly.

For $\mathrm{F}_{\text {is }}$ estimation, 45 markers for the NA population and 40 markers for the SA population fit the criteria of being strongly polymorphic, with allelic frequencies of $30-70 \%$. Ten of these markers in the NA population and 15 in the SA population showed significant linkage disequilibrium $(P<0.05)$ and were removed from $F_{\text {is }}$ calculations to fit the assumption of independently segregating markers. Thus, calculations of $F_{\text {is }}$ values were performed using 35 and 25 independently segregating markers for the NA and SA populations, respectively.

Inbreeding within populations.-To determine the mating behavior of $U$. maydis in the NA and SA cornfields, $\mathrm{F}_{\text {is }}$ was calculated for each population. In a randomly mating population at Hardy-Weinberg equilibrium (HWE), heterozygotes will be represented in the population at a frequency predicted by the individual allele frequencies and the average $\mathrm{F}_{\text {is }}$ will be zero (Hartl and Clark 1997). For the NA population, the average $F_{\text {is }}$ was $-0.08( \pm 0.09,2 \mathrm{SE})$, not statistically different from zero, and consistent with a randomly mating population. The $\mathrm{F}_{\text {is }}$ values for individual markers appeared to be normally distributed (FIG. 2a). For the SA population, the average $\mathrm{F}_{\text {is }}$ was $-0.02( \pm 0.10,2 \mathrm{SE})$, also consistent with a randomly mating population. However, the distribution of $F_{\text {is }}$ values for individual markers from the SA population appeared to be bimodal (Fig. 2b) and showed an Sshaped curve on the Wilk-Shapiro Rankit Plot (data not shown). Although the values of the NA and SA $U$. maydis populations were slightly different, this difference falls within the range explained by sampling error.
In both populations, heterozygosity in a few polymorphic markers demonstrated significant departures from HWE. For the NA population, 23\% (8 of $35)$ of the markers had levels of heterozygosity significantly different from zero $(P<0.05)$, with four markers showing significantly higher and four showing significantly lower levels (FIG. 2a). Similarly, for the SA population, heterozygosity at $20 \%$ ( 5 of 25 ) of the markers differed significantly from zero $(P<$ $0.05)$, with two markers showing significantly higher values and three showing significantly lower levels (FIG. 2b). Five of the 15 markers excluded from the analysis of the SA population because of significant linkage disequilibrium also showed significant reduction in heterozygosity $\left(\mathrm{F}_{\mathrm{is}}>0.4\right)$. Markers showing significant linkage disequilibrium in the NA population were all in HWE. Differences between the two populations in distribution of $\mathrm{F}_{\mathrm{is}}$ values at individual markers (FIG. 2) might be due to a Wahlund effect (Wahlund 1928, Hartl and Clark 1997), selection for or against specific heterozygote markers or linkage to chromosome regions or genes under selection.

The Wahlund effect results from calculating expected levels of heterozygosity assuming a single random mating population, when in fact, sampling occurred across two or more populations (Wahlund 1928, Hartl and Clark 1997). Due to the fact that the SA field had been planted only recently with corn, the bimodal shape of the distribution of $F_{\text {is }}$ values (FIG. 2b) might have resulted from the independent infection of the SA cornfield by two distinct smut populations. To assess this possibility, AFLP alleles and $b$ mating-type loci were mapped onto the SA 
cornfield to establish whether alleles were nonrandomly distributed across the field. Thirteen alleles at the $b$ mating-type locus were identified for 87 of the 96 haploid sporidia in the SA population, using barcodes from Zambino et al (1997). However, no pattern was apparent by inspection of the maps (data not shown). These findings suggest that, if two independent $U$. maydis populations founded the SA field, they were evenly distributed about the field.

One explanation for high values of heterozygosity at some individual markers could be a result of linkage to the $b$ mating-type locus. Two-way contingency test for linkage to the $b$ mating-type locus found no significant association between any AFLP allele and the 13 different $b$ alleles $(G=46.3$, d.f. $=48, P=$ $0.54)$. Association between the two $b$ alleles represented at highest frequency $\left(b_{5}=0.20\right.$ and $b_{17}=$ 0.16) and any AFLP allele, including those exhibiting shared polymorphisms with the NA population and those markers showing significant deviations from HWE, also were tested. No significant associations were found for any subset of markers $(P>0.50)$, suggesting that departure from HWE values were not due to associations with the $b$ mating-type locus.

Random mating with recombination would result in low levels of association of alleles among the haploid cells generated by meiosis (tetrad sporidia). To test this using a phylogenetic method, maximum parsimony was used (PAUP 4.0b5, Swofford 2001) to determine the relationships among haploid sporidia derived from 32 individual teliospores (tetrads) in each population. Each teliospore produced four haploid sibling sporidia. The most parsimonious tree demonstrates a "star" phylogeny for both NA and SA populations, consistent with sexually reproducing and randomly mating populations (FIG. 3). For the NA field, sibling sporidia from half (16 of 32) of the teliospores clustered together but only four clusters were supported by a bootstrap value of $80 \%$ or higher. For the SA cornfield, 28\% (9 of 32 teliospores) of the sibling sporidia were clustered together, with only three clusters supported by a bootstrap value of $80 \%$ or higher. In addition, one nonsibling sporidia cluster from the NA population and two in the SA population were observed, but these were not well supported by bootstrap values. Of the nonsibling haploids that clustered together in the SA population, none carried the same $b$ mating-type alleles. Lack of phylogenetic clustering among haploid sporidia derived from 32 different teliospores in each population is consistent with the observations of low mean $\mathrm{F}_{\text {is }}$, and together these results suggest little inbreeding in either population.

Comparisons between populations.-To estimate gene flow and the degree of population substructuring be-

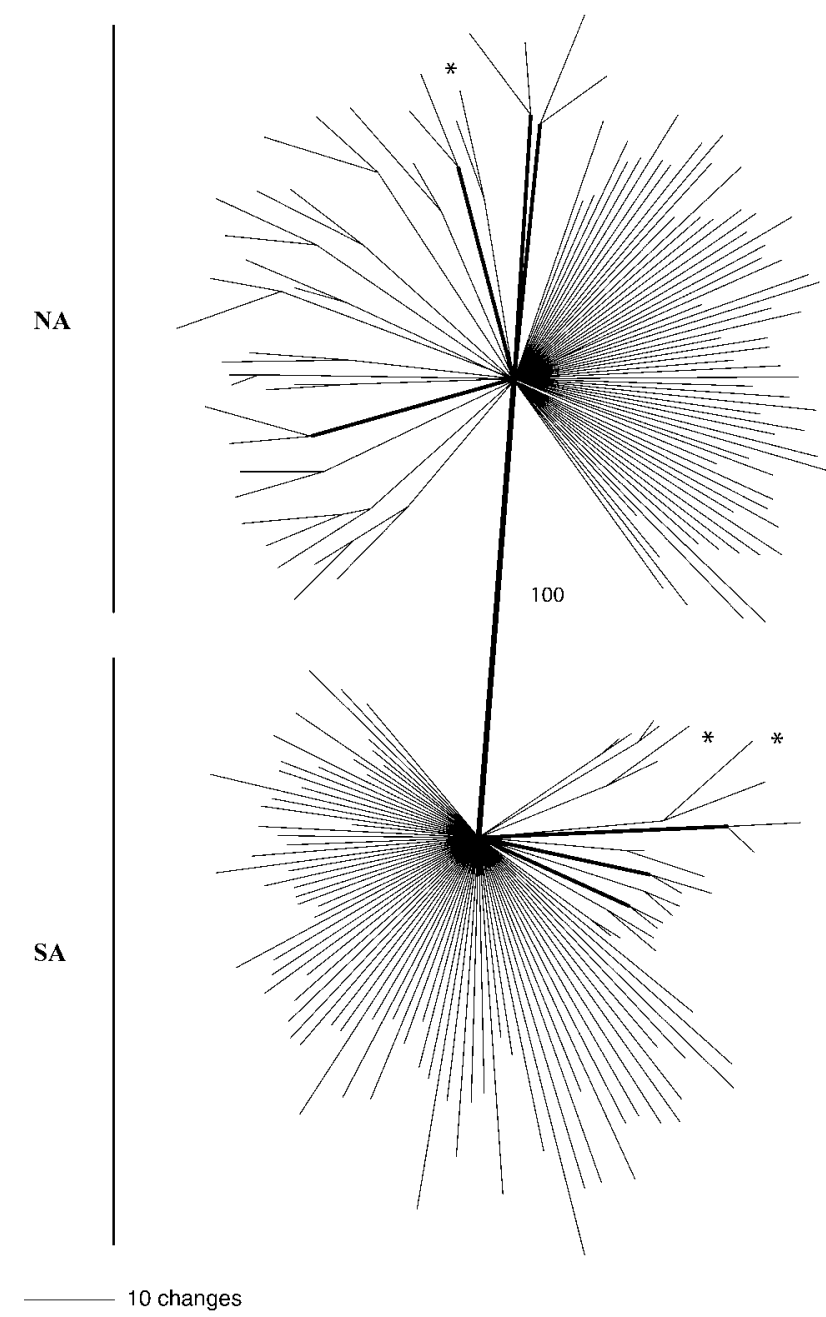

FIG. 3. Parsimony tree from analysis of AFLP data of $U$. maydis collected from two sites. Samples were collected in North America (NA) at Le Sueur, Minnesota, and in South America (SA) at Tarariras, Uruguay. The heavy bold line between populations indicates a bootstrap value of $100 \%$, while bold lines within populations indicate bootstrap values $>80 \%$. One hundred nonparametric bootstrap replicates were analyzed. Nonsibling clusters are indicated with an asterisk (*). The "star" phylogeny for the populations suggests recombination within relatively closely related but locally diverse populations.

tween the NA and SA populations, diploid genotype data were used to calculate Wright's $\mathrm{F}_{\text {st }}$ (Wright 1978) and $\mathrm{N}_{\mathrm{m}}$ (Slatkin and Barton 1989). The average $\mathrm{F}_{\mathrm{st}}$ across all markers was 0.25 , indicating a high degree of population differentiation (Wright 1978, Hartl and Clark 1997). As components of $\mathrm{F}_{\mathrm{st}}$, mean total gene diversity across both fields $\left(\mathrm{H}_{\mathrm{t}}=0.27\right)$ and mean within-field gene diversity $\left(\mathrm{H}_{\mathrm{s}}=0.20\right)$ were calculated. The moderately high level of total gene diversity was attributable mostly to diversity within populations. The low value calculated for $\mathrm{N}_{\mathrm{m}}(0.74)$ also suggests little gene flow. In addition, the parsimony 
tree supports the interpretation of very low gene flow between NA and SA smut populations because there is a clear distinction between the two populations with the association of alleles within populations supported by $100 \%$ of the bootstrap values (FIG. 3). There results are consistent with the geographic isolation of North and South American U. maydis populations.

\section{DISCUSSION}

The goals of this study were to determine the amount of inbreeding for $U$. maydis populations in two cornfields, one in NA and one in SA, and to compare genetic variation within and between these populations using AFLP markers. The problems of determining the heterozygote genotype using a codominant marker system, such as the AFLP analysis (Krauss 2000), were avoided by reconstructing the diploid state from haploid genotypes for each teliospore by tetrad analysis. Results for mean inbreeding $\left(F_{\text {is }}\right)$ values and the parsimony analysis support the hypothesis that average inbreeding within both populations is low and demonstrate that $U$. maydis is predominately an out-crossing species, whether it occurs in a well established large commercial cornfield in NA or in a relatively new, small and isolated cornfield in SA. The results further suggest that sources of haploid sporidia for mating are large enough to make selfing uncommon. The basic mating behavior is remarkably consistent in these two geographically and temporally isolated populations with contrasting cultural practices.

Different histories of the two $U$. maydis populations might have affected their genetic structure. For the SA population, 15 strongly polymorphic markers were in linkage disequilibrium, with five of these markers also showing heterozygote frequencies significantly lower than expected under HWE. In contrast, for the NA population, 10 strongly polymorphic markers were in linkage disequilibrium but heterozygosity values for these markers were not different than expected under HWE. Linkage disequilibrium decreases at a rate dependent on the recombination frequency between markers and the number of generations of recombination (Hartl and Clark 1997). Therefore it is not surprising to find more markers in linkage disequilibrium in the more recently established SA smut population. The apparent bimodal distribution of $\mathrm{F}_{\text {is }}$ values of the $\mathrm{SA}$ smut population suggests that it was founded from two sources. However, there was no evidence that the samples were obtained from across distinct smut populations. If the two hypothesized founding populations for SA differed in allele frequencies, the mixture of these pre- viously separated populations initially could result in linkage disequilibrium for those alleles, even among markers on different chromosomes (Hartl and Clark 1997). The lower number of markers demonstrating linkage disequilibrium from the older NA cornfield might reflect a longer history of recombination and longer history of maize cultivation at this location.

Christensen (1963) stated that conditions favoring infection of corn by the smut fungus are of far greater importance in creating an epidemic than conditions that favor development after infection. In both NA and SA, conditions favorable for smut infection were met at the time samples were collected but they differed for the two fields. Due to record-setting dry conditions in Uruguay, many cornfields throughout the country were harvested for silage. All observed infections were on the corn ears, suggesting infection occurred in one episode and at one point in development. Dry conditions have been shown to increase the prevalence of corn smut (Potter and Melchers 1925, Immer and Christensen 1928), perhaps by reducing host vigor, thus increasing susceptibility (Christensen 1963). In the Minnesota cornfield, wounds created by a spring hailstorm might have lead to increased incidents of infection (Christensen 1963, Alexopoulos et al 1996). Unlike the SA field, smut infections were found on tassels, leaves and stalks, as well as ears. Galls sampled from both populations resulted from mating of unrelated sporidia, suggesting that differing field conditions do not influence mating behavior of this smut fungus.

Previous studies showed that $U$. maydis populations maintain high genetic variation across various geographic scales. Valverde et al (2000) suggested that most of the variation of $U$. maydis is distributed on a local geographic scale rather than on a larger scale. They found no correlation between genetic distance and geographic distance among $U$. maydis populations across Mexico. Using RFLP analysis, May (unpublished) found genetic differentiation with a range of $0.1-0.15 \mathrm{~F}_{\mathrm{st}}$ from among corn smut populations in the eastern United States and, similar to this study, high genetic differentiation between North American and South American populations. However, differences between analysis techniques and sample sizes used in these other studies made direct comparisons impossible. Nevertheless, in this study large sample sizes were used and the consistency of out-crossing in both NA and SA populations observed suggests that the breeding structure of $U$. maydis maintains high population genetic variation across the diverse host cultural practices used throughout the Americas.

The geographic isolation of North and South American maize populations is relatively recent, dat- 
ing back only 4000-5000 y, when this crop was moved by people (Galinat 1992). Because smut occurs on no other host in NA and SA, the relatively high degree of genetic differentiation between NA and SA populations apparently has evolved over a relatively short time. Together, the prevalence of sexual recombination, little gene flow $\left(\mathrm{N}_{\mathrm{m}}=0.74\right)$, and the short time scale suggest that the genetic differentiation between these two populations is due to strong selection or to strong bottlenecks leading to drift, or both.

Previous studies on anther smuts, such as Microbotryum violaceum (Thrall et al 1993, Garr et al 1997) and Sporisorium amphilophis (Garcia-Guzman et al 1996), demonstrated that the density and distribution of host populations strongly influence the distribution of smut pathogen populations. In Uruguay, the observed distance of at least $1 \mathrm{~km}$ between the cornfield sampled and its nearest neighbor suggests that the size of interbreeding populations of $U$. maydis is on the scale of several kilometers and should be dependent on the distribution of cornfields on a regional scale.

In conclusion, the results of both inbreeding coefficients and the parsimony analysis suggest that infection of individual plants originates from a larger and more diverse inoculum source than previously had been considered, either as secondary sporidia surviving on debris or from multiple teliospores. High inbreeding would have suggested that individual $U$. maydis teliospores frequently act as single infection units, developing from mating between compatible sibling sporidia soon after germination-typical of Tilletia smut fungi. If $U$. maydis teliospores are effective as inoculum they must not commonly infect as single infection units, otherwise the mating between sibling sporidia would be enforced. The corn smut fungus is an opportunistic pathogen and is reported more often when the corn plants have experienced some stress or injury (Christensen 1963), such as drought or a hailstorm. By definition, being opportunistic means that corn smut also can survive without the plant, which this fungus might do as saprophytic sporidia or as dormant teliospores in the soil and debris. Regardless of when mating occurs after teliospore germination, this study showed that two $U$. maydis populations were both out-crossing despite their maintenance in different geographic regions, and under varying cultural practices for maize.

\section{ACKNOWLEDGMENTS}

We thank the Department of Plant Pathology and the Center for Community Genetics at the University of Minnesota, the Instituto Nacional de Investigación Agropecuaria (INIA) in Uruguay, and the NSF BioComplexity grant awarded to G. May (DMS-0083468) for financial support. We also would like to thank Alexi Balmuth, Kim Phuong Nguyen and Sandra Scherrer for their technical assistance.

\section{LITERATURE CITED}

Agrios GN. 1997. Plant pathology. 4th ed. San Diego, California: Academic Press. 635 p.

Alexopoulos CJ, Mims CW, Blackwell M. 1996. Introductory mycology. New York, New York: John Wiley and Sons, Inc. 869 p.

Analytical Software. 1998. Statistix for windows. Version 2.0, user's manual. Siegel J, ed. Tallahassee, Florida: Analytical Software. 319 p.

Andrews DL, Egan JD, Mayorga ME, Gold SE. 2000. The Ustilago maydis $u b c 4$ and $u b c 5$ genes encode members of a MAP kinase cascade required for filamentous growth. Mol Plant-Microbe Interact 7:781-786.

Anikster Y, Szabo LJ, Eilam T, Manisterski J, Koike ST, Bushnell WR. 2004. Morphology, life cycle biology, and DNA sequence analysis of rust on garlic and chives from California. Phytopathology 94:569-577.

Banuett F, Herskowitz I. 1996. Discrete developmental stages during teliospore formation in the corn smut fungus, Ustilago maydis. Development 122:2965-2976.

. 1995. Genetics of Ustilago maydis, a fungal pathogen that induces tumors in maize. Annu Rev Genet 29: 179-208.

Burt A, Carter DA, Koenig GL, White TJ, Taylor JW. 1996. Molecular markers reveal cryptic sex in the human pathogen Coccidioides immitis. Proc Natl Acad Sci USA 93:770-773.

Christensen JJ. 1963. Corn smut caused by Ustilago maydis. Monograph No. 2. St. Paul, Minnesota: American Phytopathological Society. $41 \mathrm{p}$.

Galinat WC. 1992. Evolution of corn. Adv Agron 47:203231.

Garcia-Guzman G, Burdon JJ, Ash JE, Cunningham RB. 1996. Regional and local patterns in the spatial distribution of the flower-infecting smut fungus Sporisorium amphilophis in natural populations of its host Bothriochloa macra. New phytol 132:459-469.

Garr SS, Hughes C, Welch J, Brown SA, Perlin MH. 1997. Correlation of haplotypes of a fungal plant pathogen with their respective host species of origin. Plant dis 81:936-941.

Gillissen B, Bergemann J, Sandmann C, Schroeer B, Bolker M, Kahmann R. 1992. A two-component regulatory system for self/non-self recognition in Ustilago maydis. Cell 68:647-657.

Hartl DL, Clark AG. 1997. Principles of population genetics. 3rd ed. Sunderland, Massachusetts: Sinauer Associates Inc. 542 p.

Hartmann HA, Krüger J, Lottspeich F, Kahmann R. 1999. Environmental signals controlling sexual development of the corn smut fungus Ustilago maydis through the transcriptional regulator Pfr1. Plant Cell 11:1293-1305.

Immer FR, Christensen JJ. 1928. Influence of environmen- 
tal factors on the seasonal prevalence of corn smut. Phytopathology 18:599-602.

Krauss SL. 2000. Accurate gene diversity estimates from amplified fragment length polymorphism (AFLP) markers. Mol Ecol 9:1241-1245.

Levene H. 1949. On a matching problem in genetics. Ann Math Stat 20:91-94.

Potter AA, Melchers LE. 1925. Study of the life history and ecologic relations of the smut of maize. J Agr Res 30: 161-173.

Rowell JB, DeVay JE. 1954. Genetics of Ustilago zeae in relation to basic problems of its pathogenicity. Phytopathology 44:356-362.

Shurtleff MC. 1980. Compendium of corn diseases. 2nd ed. St. Paul, Minnesota: American Phytopathological Society Press. 105 p.

Slatkin M, Barton NH. 1989. A comparison of three indirect methods for estimating average levels of gene flow. Evolution 43:1349-1368.

Snetselaar KM, Mims CW. 1992. Sporidial fusion and infection of maize seedlings by the smut fungus Ustilago maydis. Mycologia 84:193-203.

- - 1993. Infection of Maize stigmas by Ustilago maydis: light and electron microscopy. Phytopathology 83:843-850.

-1 1994. Light and electron microscopy of Ustilago maydis hyphae in maize. Mycol Res 98:347-355.

Sokal RR, Rohlf FJ. 1981. Biometry. 2nd ed. San Francisco, California: W.H. Freeman and Co. 859 p.

Swofford DL. 2001. PAUP*. Phylogenetic Analysis Using Parsimony (*and other methods). Version 4. Sunderland, Massachusetts: Sinauer Associates. 128 p.

Thrall PH, Biere A, Antonovics J. 1993. Plant life history and disease susceptibility-the occurrence of Ustilago violacea on different species within the Caryophyllaceae. J Ecol 81:489-498.

Valverde ME, Vandemark GJ, Martinez O, Paredes-Lopez O. 2000. Genetic diversity of Ustilago maydis strains. World J Microbiol Biotechnol 16:49-55.

Vos P, Hogers R, Bleeker M, Reijans M, van de Lee T, Hornes M, Frijters A, Pot J, Peleman J, Kuiper M, Zabeau M. 1995. AFLP: a new technique for DNA fingerprinting. Nucleic Acids Res 23:4407-4414.

Wahlund S. 1928. Composition of populations from the perspective of the theory of heredity. Hereditas 11:65-105.

Webster J. 1980. Introduction to fungi. 2nd ed. Cambridge, England: Cambridge University Press. 669 p.

Weir BS. 1979. Inferences about linkage disequilibrium. Biometrics 35:235-254.

Wright S. 1965. The interpretation of population structure by F-statistics with special regard to systems of mating. Evolution 19:395-420.

. 1978. Evolution and the genetics of populations. Vol. 4. Variability within and among natural populations. Chicago, Illinois: University of Chicago Press. $580 \mathrm{p}$.

$\mathrm{Xu} \mathrm{JR.} \mathrm{2000.} \mathrm{MAP} \mathrm{kinase} \mathrm{in} \mathrm{fungal} \mathrm{pathogens.} \mathrm{Fungal} \mathrm{Gen-}$ et Biol 31:137-152.

Yeh FC, Yang RC, Boyle TBJ, Ye Z, Xiyan JM. 1997. POPGENE, the user-friendly shareware for population genetic analysis. Edmonton, Canada: Molecular Biology and Biotechnology Centre, University of Alberta, Canada. 28 p.

Zambino PJ. 2002. Dry grinding at near-ambient temperatures for extracting DNA from rust and other fungal spores. Bio Techniques 33:48-51.

, Groth JV, Lukens L, Garton JR, May G. 1997. Variation at the $b$ mating type locus of Ustilago maydis. Phytopathology 87:1233-1239. 